\title{
Importancia de la nutrición: primeros 1,000 días de vida
}

\author{
Importance of Nutrition: first 1,000 days of life
}

Norma González Hernández*, Gabriela Alejandra López Robles**, Lidia María Prado López***

\section{RESUMEN}

La nutrición en los primeros 1000 días de vida es la clave esencial para una futura vida sana, ya que este subgrupo de la población es propenso a los desequilibrios e insuficiencias dietéticas. Es de vital importancia una correcta nutrición para apoyar el crecimiento y desarrollo adecuado. Además es importante controlar todos los trastornos nutricionales que ocurren en la gestación y en los primeros 2 años ya que subsecuentemente aumentan la morbi-mortalidad, que repercute permanentemente sobre la salud. En los últimos años, existe un considerable interés sobre los efectos que tiene el excesivo aumento ponderal durante la infancia, debido a que el desarrollo de tejido graso en este período es un factor determinante en la composición corporal del adulto.

La leche materna es el alimento único e irremplazable, debido a que suministra todos los nutrientes que garantizaran un desarrollo adecuado. La OMS la recomienda durante los 2 primeros años.

La misión de los pediatras durante esta etapa de ventana crítica es promover la lactancia materna exclusiva, ya que hay menor riesgo de diarreas, otitis media, neumonía, alergias alimentarias, infecciones urinarias, DM tipo 2, HTA y obesidad. El reloj de los 1000 dias no se puede reiniciar, debemos ser futuristas y tener los conocimientos adecuados sobre la alimentación en este importante periodo.

\section{PALABRAS CLAVES}

nutrición, lactancia materna, proteínas de alto valor biológico, aminoácidos esenciales, anemia por deficiencia de hierro.

*Gastroenteróloga Pediatra, Pediatra de turno Instituto Hondureño de Seguridad Social

** Médico Residente primer año del Posgrado de Pediatría, UNAH-VS

*** Pediatra, HNMCR, Profesor de la Escuela Universitaria de la Ciencias de la Salud.

Dirigir correspondencia a:christandng@hotmail.com

Recibido: 13 de diciembre 2016 Aprobado: 22 de febrero 2017

\section{ABSTRACT}

The attention during the first 1000 days is the essential key to a healthy future life, as this subgroup of the population is prone to dietary disequilibrium and insufficiencies. It's of vital importance, a correct nutrition during the first thousand days, to support an adequate growth and development. Besides, it's important to control nutritional disorders that occur during gestation and in the first two years of life, which subsequently increase morbi-mortality, as it permanently impacts on the health of the individual. In the last years, there's been a considerable interest in the effects of excessive weight gain during childhood, due to the fact that the development of fatty tissue during this period is a determinant factor of an adult corporal composition.

Breastmilk is a unique and irreplaceable aliment, because it provides all the nutrients that guarantee an adequate development. WHO recommend it during the first 2 years.

Pediatricians mission during this phase of life is to promote exclusive breastfeeding so that the risk of infectious, immunologic and chronic diseases decreases. This is why pediatrician's role is to protect, promote and support breastfeeding. The 1000 days clock cannot be reset, so we have to be futurist and have the adequate knowledge about feeding in this important period.

\section{KEY WORDS}

Nutrition, Breastfeeding, proteins of high biological value, essential amino acids, iron deficiency anemia faith.

\section{INTRODUCCIÓN}

La alimentación en los primeros 1,000 días se refiere a la alimentación en dos etapas de la vida, la primera corresponde a los 270 días desde la concepción hasta el nacimiento, y la segunda a los 2 primeros años de vida (730 días). 
Este período es la ventana crítica en el desarrollo del niño, ya que implica cambios transcendentales para la salud y brinda una oportunidad única para que los niños obtengan beneficios nutricionales e inmunológicos que necesitarán el resto de su vida. $(1,2,3)$

En esta etapa se forman la mayor parte de los órganos, tejidos y también el potencial físico e intelectual de cada niño. Se desarrollará la inteligencia, se formarán los hábitos alimentarios perdurables y se definirá la salud nutricional del niño ya que una buena alimentación en estos "mil días críticos" será un seguro de salud para su vida futura. ${ }^{(4)}$

Los daños que se generen durante estos primeros mil días tendrán consecuencias irreversibles en el individuo, por lo que la prevención es fundamental.

Se presenta a continuación una revisión bibliográfica sobre la suplementación de la madre durante el embarazo y lactancia y la alimentación y suplementación en el hijo en los primeros 2 años de vida.

\section{EPIGENETICA Y PROGRAMACIÓN FETAL}

La nutrición se considera un factor ambiental que influye en diversas enfermedades, tanto crónicas como autoinmunes. Este efecto se inicia a nivel epigenético durante el embarazo. Debido a que la nutrición de la madre afecta el crecimiento del feto y de igual forma impacta en el desarrollo durante su infancia, se le denomina programación fetal. ${ }^{(5)}$ Para mejorar el estado nutricional de los niños durante esta etapa, es recomendable que todas las mujeres tengan una nutrición adecuada, antes de la concepción y durante la gestación. ${ }^{(5)}$

El embarazo es una situación especial en la que aumentan las necesidades de energía, proteínas, vitaminas y minerales. Debido a que los bebes reciben a través de la placenta todos los nutrientes de la madre, se considera que la dieta de la madre es uno de los factores extrínsecos de mayor influencia sobre el crecimiento y desarrollo fetal.
Las condiciones ideales maternas para un embarazo sin complicaciones son: madre edad: 19 - 34 años con IMC 20 - $24.9 \mathrm{~kg} / \mathrm{m}^{2}$, no fumadoras, no alcohólicas, no drogadicta, no portadora de VIH, sin patología crónica, sin anemia ni déficit de hierro, con una nutrición adecuada y balanceada y en caso de tener esta, con una adecuada suplementación.

\section{SUPLEMENTACIÓN EN EL EMBARAZO}

Desde el punto de vista nutricional, un suplemento es un aporte extra de nutrientes. La FDA los define como sustancias que intentan suplementar la dieta a base de uno o más componentes dietéticos y que pueden administrarse de distintas formas, con el fin de complementar las necesidades nutricionales particulares determinadas por distintas situaciones físicas, fisiológicas, metabólicas o patológicas específicas. ${ }^{(6)}$

En el periodo previo a embarazarse y durante el embarazo la madre debe recibir suplementos de ácido fólico, hierro, yodo, calcio, zinc, cobre entre otros.

El ácido fólico interviene en la síntesis proteica del ADN. Durante la embriogénesis, las células son susceptibles al déficit de ácido fólico, lo cual produce defectos del tubo neural debido a falla en la fusión del mismo entre los días 21-27 de vida embrionaria. Los niveles de ácido fólico deben de estar elevados durante el período de la concepción y hasta 30 días posterior que es cuando finaliza el cierre del tubo neural. La madre debe recibir la dosis de $4 \mathrm{mg} /$ día. La suplementación con ácido fólico supone la intervención más importante y efectiva para la disminución de los defectos congénitos. ${ }^{(7)}$

La anemia ferropénica es la deficiencia nutricional más frecuente en la embarazada. Su déficit perjudica el rendimiento cognitivo y el desarrollo físico de los recién nacidos. Es por esto que se debe suplementar a la madre con 30 mg/día de hierro elemental al día (150 mg de sulfato ferroso y $300 \mathrm{mg}$ de gluconato ferroso). ${ }^{(7)}$

El iodo es un mineral imprescindible en la síntesis de la hormona tiroidea y tiene un papel 
fundamental en el metabolismo celular y en el proceso de desarrollo y funcionamiento de todos los órganos especialmente del cerebro. No se puede almacenar por lo que se debe ingerir diariamente. Su déficit produce bocio endémico, abortos a repetición, retraso en el crecimiento, retraso mental y cretinismo. La consecuencia más grave es la alteración en el desarrollo cerebral y neurológico del feto, la cual es ya irreversible al nacer. La OMS declara que su déficit es la primera causa, después de la inanición extrema, de retraso mental y parálisis cerebral. La dosis en la mujer gestante recomendada por la OMS es 220-300 $\mu \mathrm{g}$ al día. ${ }^{(7)}$

La fuente principal de la vitamina D es la exposición a la luz solar, mientras que el aporte de la dieta tiene un papel secundario. Las necesidades diarias de vitamina $\mathrm{D}$ a través de la ingesta es de $5 \mathrm{mcg}$ (200 UI). Su requerimiento no aumenta durante el embarazo y la lactancia, por lo que no es necesario suplementarla en estos periodos. En caso de haber deficiencia grave se asocia a retardo del crecimiento intrautero, hipocalcemia, tetania y alteraciones en el esmalte dental. Se reserva su suplementación en casos de hipoparatiroidismo materno.

El Calcio es esencial para la estructura ósea, la transmisión del impulso nervioso, la excitabilidad neuromuscular, la coagulación, permeabilidad celular y la activación enzimática. Durante el embarazo aumenta su absorción intestinal, con el objetivo de facilitar su aporte desde la madre al feto, manteniendo los niveles plasmáticos y óseos maternos. Se relaciona con la aparición de preclampsia y prematuridad. La suplementación de calcio reduce el $50 \%$ de la incidencia de preclampsia. En países en desarrollo se suplementa 1,000 mg diarios. ${ }^{(7)}$

El Zinc es un nutriente esencial. Se considera que el $82 \%$ de las gestantes de todo el mundo no ingieren zinc en cantidades suficientes para satisfacer las necesidades básicas. Cuando el déficit es importante se ponen en marcha varios mecanismos que afectan la embriogénesis y el desarrollo fetal, provocando malformaciones congénitas como defectos del pala- dar, cardiacas, urológicas, esqueléticas y cerebrales. Cuando la deficiencia es moderada se aprecia mayor riesgo de ruptura prematura de membrana y parto prematuro. El consumo de cereales y vegetales no suplementados interfiere con la absorción del hierro contenido en la leche materna, produciéndose así déficit de este, zinc y vitaminas. Su suplementación debe ser $15 \mathrm{mg}$ al día de Zinc. ${ }^{(7-8)}$

\section{ALIMENTACIÓN SALUDABLE EN EL RECIEN NACIDO Y LACTANTE.}

La leche materna es el alimento único e irremplazable debido a que suministra todos los nutrientes que garantizan un desarrollo adecuado, previene infecciones y estrecha la relación del binomio madre-hijo. ${ }^{(9-10)}$ La composición nutricional de la leche materna es influenciada en parte por la alimentación materna, por lo que durante este período debe tener una completa y adecuada nutrición. Es crucial que los médicos indiquen apego precoz durante las primeras horas de vida en las salas de maternidad y eduquen a la madre a alimentar al pecho materno de manera exclusiva al recién nacido y lactante, orientándola sobre la importancia de mantener una adecuada alimentación, para así lograr que la lactancia materna sea siempre el pilar fundamental de la alimentación del niño en la primera etapa de vida. Una mejor nutrición en esta ventana crítica del desarrollo humano no sólo salva vidas sino también mejora el desarrollo cognoscitivo, los logros escolares y fomenta el capital humano. ${ }^{(11-12)}$

La Lactancia materna exclusiva se recomienda según los distintos organismos OMS, Academia Americana de Pediatría (AAP), Sociedad Europea para Gastroenterología, Hepatología y Nutrición Pediátrica (ESPGHAN) hasta los primeros 6 meses de vida, y se recomienda la continuación de la lactancia materna después de introducir la alimentación complementaria10 y mantenerla durante los primeros 2 años, hasta que la madre y el niño así lo deseen. ${ }^{(12-15)}$

La lactancia materna ejerce un efecto protector contra las infecciones y la atopia, debido a efectos inmunomoduladores sobre la respuesta inmune neonatal. ${ }^{(16-17)}$ La leche humana contie- 
ne numerosos componentes relacionados con la inmunidad tales como; IgA, leucocitos, oligosacaridos, lisozima, lactoferrina, interferón gama, nucleótidos, citoquinas y otros. Estos componentes ofrecen una protección pasiva al tracto gastrointestinal y en cierta medida al tracto respiratorio superior, lo que evita la adhesión de patógenos a la mucosa y así protege contra las infecciones invasivas. ${ }^{(9,18-21)}$

El tipo de lactancia, la duración y el momento de introducción de los alimentos sólidos en la dieta, se han considerado como puntos importantes en la patogenia de algunas enfermedades no transmisibles como la alergia, la obesidad, Diabetes Mellitus y la enfermedad celiaca. Por esto es fundamental analizar las recomendaciones acerca de la alimentación en este período crucial.

La ESPGHAN recomienda que la alimentación complementaria no debe introducirse antes de las 17 semanas, ni después de las 26 semanas. ${ }^{(22)}$

La alimentación infantil debe realizarse en familia y en un entorno agradable, para estimular el apetito y los buenos hábitos alimentarios. ${ }^{(9)}$

La gran mayoría de alimentos utilizados para ablactación en nuestros países (cereales, granos y vegetales) son carentes de micronutrientes y zinc. Por lo que la estrategia de suplementarlos con micronutrientes, así como la selección de alimentos ricos en hierro y zinc de acuerdo a las necesidades del lactante son conductas valiosas que si se realizaran en forma sistemática ayudarían a corregir el problema. ${ }^{(23)}$

Los objetivos de la alimentación complementaria son: 1. Proporcionar una dieta adecuada que cubra los requerimientos nutricionales del niño para un crecimiento y desarrollo óptimo, 2. Desarrollar buenos hábitos que en un futuro prevengan obesidad, dentición deficiente, diabetes, enfermedades cardiovasculares, 3. Suministrar una dieta equilibrada y completa que evite deficiencias de nutrientes específicos (hierro, zinc, calcio, vitamina A y D) y 4 . Desarrollo del gusto y palatabilidad: diferentes texturas, olores y sabores ya que esta es la base para una alimentación saludable en un futuro no lejano.

\section{SUPLEMENTACIÓN EN EL NIÑO}

Existen pautas para suplementar las vitaminas y minerales en el niño. A partir del tercer día de vida, se inicia la vitamina $D$, al sexto mes el complejo de vitaminas B y hierro, aunque la suplementación varía dependiendo de ciertas características del bebe como la prematurez, antecedente de anemia/ictericia, bajo peso al nacer, entre otros.

La Vitamina K es necesaria para la síntesis de los factores de la coagulación V, VII IX y X. Su déficit se asocia a trastornos de la coagulación. La vitamina $\mathrm{K}$ atraviesa la placenta pero en cantidad muy limitada. Los niveles del feto y del neonato son muy bajos por lo que se debe realizar su administración sistemática a todos los recién nacidos a una dosis de 0.5 a $1 \mathrm{mg}$ a el primer día de vida.

La fuente óptima de calcio durante el primer año de vida es la leche materna. La biodisponibilidad del calcio en la leche materna es mayor que en las fórmulas de inicio (58\% y $38 \%$ respectivamente). Para obtener niveles comparables a la leche materna, se aumentaron las concentraciones de calcio en las fórmulas. Los requerimientos rondan los $700 \mathrm{mg} /$ día. ${ }^{(24)}$

El hierro y zinc están presentes en la LM a una concentración relativamente baja pero su disponibilidad y absorción es elevada. Si las reservas de hierro de la madre son adecuadas, los niños que nacen a término tienen reservas de hierro y zinc que permiten, satisfacer sus necesidades los primeros 6 meses; dado que los depósitos fetales se establecen en el último trimestre del embarazo los prematuros presentan déficit y requieren suplementación conestos nutrientes desde los primeros meses de vida. ${ }^{(25)}$

El hierro es un cofactor de enzimas cerebrales importante en la síntesis de neurotransmisores y tiene una influencia sobre el crecimiento dendrítico del hipocampo. ${ }^{(25)}$

Existe evidencia de que la anemia por déficit de hierro se asocia con una menor acción en los índices de desarrollo de los niños. La mayor 
parte de la evidencia proviene de observaciones en las diferencias del estado basal entre niños con anemia ferropriva y niños no anémicos. La deficiencia severa de hierro da como resultado una actividad más pobre. Los infantes y niños menores con anemia ferropriva presentan frecuentemente dificultades en el lenguaje, coordinación motora y el mantenimiento del equilibrio corporal, quizá lo que parece más evidente es una alteración en los niveles de atención, con respuestas respuestas inadecuadas, en las diversas variaciones del humor y en el estado de ánimo. ${ }^{(26)}$

Aunque la administración de hierro en niños que viven en condiciones socioeconómicas precarias, con muy poca estimulación y bajo nivel educativo, no parece ser capaz de promover un desarrollo psicomotor normal, las pruebas de desarrollo mental y psicomotor tienen un score inferior en infantes y niños pequeños que tienen anemia en comparación con aquellos que solo presentan deficiencias de hierro. La mayoría de estudios muestran que es necesario tratar precozmente la anemia ferropriva y la deficiencia de hierro severa con el fin de garantizar un adecuado desarrollo mental, motor y así asegurar el futuro del niño. ${ }^{(26)}$

\section{MALA PROGRAMACIÓN}

En los últimos años se han producido importantes cambios en el estilo de vida de la población y con ello en la alimentación de niños y adolescentes. El avance tecnológico alimentario y culinario, incorporación de la mujer en el trabajo, estructura familiar, publicidad y la incorporación más temprana de los niños en la escuela, entre otros factores pueden condicionar un consumo de alimentos de baja calidad nutricional. ${ }^{(4)}$

Las tasas de sobrepeso y obesidad están en aumento en niños en edad preescolar, el estado nutricional de la madre y la alimentación en los primeros 2 años de vida se consideran una ventana critica para su riesgo. ${ }^{(27)} \mathrm{La}$ obesidad y diabetes mellitus materna es un factor que contribuye a obesidad y a la diabetes mellitus en edad temprana. ${ }^{(5)}$

Esto ha hecho que el ministerio de Sanidad de
Honduras haya establecido la "Estrategia para la nutrición, actividad física y prevención de obesidad (NAOS)". Dichas estrategias deben iniciarse en la infancia, a través de su promoción en Centros de Atención Primaria. ${ }^{(3)}$

La microbiota intestinal es responsable de la integridad y función del tracto gastrointestinal por medio del efecto de barrera, estimulación del sistema inmune y síntesis de sustancias. El efecto de barrera es contra el crecimiento de bacterias patógenas y se ejerce por medio de una competencia de alimentos entre las bacterias mutualistas y patógenas. Además, ese desequilibrio de la microbiota ejerce alteraciones en el $\mathrm{pH}$ intraluminal. La microbiota estimula el sistema inmune al activar los tejidos linfoides asociados al intestino; más del $70 \%$ del tejido linfoide se encuentra en el intestino y un cuarto de este se concentra en la mucosa.

Avances recientes han permitido coleccionar más datos sobre las secuencias de ADN y metabolitos en el ser humano. Esto ha incrementado el entendimiento sobre las conexiones entre la microbiota intestinal y los metabolitos. Se ha identificado cómo la microbiota determina niveles de metabolitos específicos, cómo se desarrolla el perfil de metabolitos en los niños y prospectos para evaluar el estado físico de una persona en base a su microbiota y/o sus metabolitos. ${ }^{(38)}$ Por lo tanto, el metaboloma es el conjunto dinámico de moléculas y elementos químicos presentes en un organismo vivo como en la microbiota y nos refleja el estado metabólico del tracto gastrointestinal. Nos permite describir el estado de la microbiota haciendo posible el estudio de respuestas celulares, mecanismos de defensa y mecanismos de homeostasis (almacenamiento y redistribución de la energía. ${ }^{(28-30)}$

La microbiota intestinal y por la misma razón, los probióticos específicos pueden ayudar a la normalización de las propiedades de la microbiota aberrante, a las funciones de barrera del intestino, regulación de la secreción de los mediadores inflamatorios, así como al desarrollo del sistema inmunológico durante el período crítico de programación inmunológica, metabólica y microbiológica. 
Se calcula que a nivel mundial más de 42 millones de niños tienen sobrepeso. Aun cuando se atribuye generalmente a una mayor abundancia de alimentos y menor actividad física, existe una evidencia creciente que sugiere que la predisposición a la obesidad puede adquirirse también en etapas más tempranas de la vida.

Los niños con bajo peso y que muestran rápida recuperación del crecimiento en las primeras semanas de vida tienen un alto riesgo de obesidad. Lo mismo sucede con los bebes que nacen grandes para la edad gestacional.

\section{CRECIMIENTO Y DESARROLLO}

En condiciones fisiológicas el peso al nacer se cuadriplica durante los 2 primeros años de vida y la talla se duplica a los 4 años. A partir del primer año de vida el crecimiento aproximado es de $12 \mathrm{~cm}$ por año. La ganancia de peso es aproximadamente de 2 a $2.5 \mathrm{~kg}$ por año. Se produce un aumento de las extremidades inferiores, se pierde agua, grasa, aumenta la masa muscular y el depósito mineral óseo. ${ }^{(4)}$

En los dos primeros años de vida el niño adquiere más masa magra que grasa y posteriormente esta proporción se invierte. Esto es determinante ya que masa magra significa: músculos, huesos, vísceras y cerebro. ${ }^{(31)}$ La velocidad de crecimiento neural (cerebro, duramadre, aparato óptico, médula espinal, región etmoidal y cavidades nasales) es alta durante los primeros años de vida; Ilama la atención que durante el primer año se alcanza un $40 \%$ de su crecimiento, y a los 5 años alcanza aproximadamente el 85\% de la masa neural que tendrá cuando sea adulto. ${ }^{(4)}$ Las alteraciones que ocurran durante los primeros 2 años de vida generarán morbimortalidad futura afectarán el desarrollo mental motor y a largo plazo puede asociarse abajo rendimiento intelectual, disminución en la capacidad de trabajo y alteraciones en la capacidad reproductiva. ${ }^{(1)}$ La ganancia rápida de peso desde los dos hasta los cuatro años se asocia a incremento de la masa grasa, y consecuentemente con el desarrollo de Diabetes Mellitus, Obesidad, Hipertensión arterial, síndrome metabólico. Es importante que haya un control en la ganancia de tejido graso en esta etapa.

\section{REQUERIMIENTOS NUTRICIONALES}

La distribución de la energía en la dieta debe de ser: carbohidratos 50-60\%; Proteínas 10-15\%; Grasas < 30\%. Los niños deben de realizar al menos 5 comidas distribuidas en: desayuno, merienda 25\%; almuerzo 35\%; merienda $10 \%$; cena $30 \% .^{(32)}$

\section{LÍPIDOS}

Desde el punto de vista nutricional, el cerebro tiene necesidades específicas como hierro, colina, ácido fólico, zinc, yodo, ácido linolénico y ácido linoléico y sus derivados Ácido Decosahexaenóico (DHA) y el ácido araquidónico (ARA). Estos últimos son ácidos grasos poliinsaturados con un importante rol en el desarrollo del sistema nervioso central. Las deficiencias de todos ellos en esta etapa de gran crecimiento y vulnerabilidad pueden repercutir en retrasos en el desarrollo que sean irreversibles.

El aporte de colina es necesario para el correcto desarrollo neuronal. La colina actúa a nivel del cierre del tubo neural, tiene efectos sobre la metilación del ADN y la expresión génica, es un componente de la acetilcolina, es un constituyente importante de los fosfolípidos de membrana y de la mielina. ${ }^{(33)}$

El Sistema Nervioso Central contiene la segunda mayor concentración de lípidos, solo después del tejido adiposo. Aproximadamente 50 a $60 \%$ del peso seco del cerebro son lípidos, de los cuales $35 \%$ son ácidos grasos de cadena larga, principalmente DHA; este es esencial para la síntesis, mantenimiento y función de los tejidos cerebrales, para mantener la salud del sistema inmune y además, está involucrado en el metabolismo de la dopamina y serotonina. El lactante obtiene DHA preformado de la leche materna o de fórmulas fortificadas con este.

Varios estudios han demostrados que los niños alimentados con fórmulas fortificadas con DHA tienen puntuaciones significativamente más altas en las pruebas psicomotoras, pruebas de agudeza visual y en los índices de desarrollo mental. ${ }^{(4)}$ 
El sistema inmune es particularmente sensible al estrés oxidativo ya que las membranas de sus células son ricas en ácidos grasos poliinsaturados de cadena larga.

\section{HIDRATOS DE CARBONO}

El principal hidrato de carbono en la leche materna es la lactosa. Este carbohidrato es un nutriente específico en el primer año. La mayor cantidad de enzima lactasa que la metaboliza proviene de la leche materna. Su alta concentración en la leche humana facilita la absorción del calcio y hierro y promueve la colonización intestinal con el Lactobacillus bifidus.

\section{PROTEÍNA EN LA INFANCIA}

En menores de 6 meses, la mayor parte de las proteínas proceden del consumo de leche y sus derivados; en edades posteriores, del consumo de carnes, pescados, huevo y en segundo lugar, de los productos lácteos. ${ }^{(34)}$

La ingesta proteica estimula la secreción del factor de crecimiento semejante a la insulina (IGF-I), que promueve la proliferación celular, acelera el crecimiento y aumenta el tejido adiposo. ${ }^{(32)}$

La lactancia materna exclusiva cubre los requerimientos aproximadamente hasta los 5-6 meses, provee un ingreso de proteínas de 2.1 $\mathrm{g} / \mathrm{kg} /$ día durante el primer mes y de $1.1 \mathrm{~g} / \mathrm{kg} /$ día para el período de 4-6 meses. Entre los 6-12 meses los niños deben recibir un $50 \%$ de las proteínas de alto valor biológico y los mayores de un año un $20-40 \%$. ${ }^{(35)}$

\section{Tabla No. 1: Requerimiento de proteínas de acuerdo a la edad.}

\begin{tabular}{|cc|}
\hline Edad (años) & NSI (g/kg/d)* \\
\hline $0-0.5$ & 2.2 \\
$0.6-1$ & 1.6 \\
$1-3$ & 1.2 \\
\hline
\end{tabular}

$\mathrm{NSI}$ : Nutritional System Intake

* FAO-OMS-ONU

Fuente: 1er. Consenso Centro Americano. Alimentación en el primer año de vida. Sociedad Centroamericana de Gastroenterología, Hepatología y Nutrición Pediátrica. ${ }^{(23)}$
El perfil de aminoácidos es un aspecto clave de la leche humana para la calidad en sus proteínas, ya que estas dependen de su composición en aminoácidos esenciales, de la capacidad para reponer el nitrógeno del organismo y de que pueda ser totalmente utilizada.(25)

Un aminoácido esencial deficitario en la dieta limita la utilización de los demás aminoácidos, condicionando la cantidad total de proteínas que se sintetiza. Los alimentos con proteínas de alto valor biológico son la leche y sus derivados, carnes y la clara de huevo. ${ }^{(33)}$ La taurina, acido glutámico y glutamina son los aminoácidos libres más abundantes en la leche humana y comprenden casi el 50\%. ${ }^{(25)}$

Un aspecto importante de resaltar es que el niño alimentado al pecho materno no necesita una ingesta complementaria de agua, en cambio, el niño alimentado con formula debe de recibir agua como complemento.

Se han realizado diversos estudios observacionales sobre cómo la lactancia materna influye en el crecimiento y en la función renal durante la vida y se demostró que los niños que recibieron lactancia materna en forma exclusiva durante al menos 4 meses tenían volúmenes renales más pequeños y mejores tasas de filtración glomerular con menor riesgo de microalbuminuria, en comparación con los que recibieron fórmula. ${ }^{(37)}$

Las diferencias proteicas en la leche materna y de vaca se relacionan con su concentración y tipo de proteínas. En la leche materna se encuentra la alfa lactoalbumina, proteína de alto valor biológico, la lactoferrina, lisozimas e inmunoglobulinas que comprenden alrededor del $30 \%$ de las proteínas totales de la leche madura. La beta-lactoglobulina, que es la proteína sérica más abundante en la leche de vaca y no se encuentra en la leche humana, por lo que se considera tradicionalmente como el alérgeno más importante de la leche de vaca. El contenido de proteínas totales en la leche humana es de $0.9 \mathrm{gr} / 100 \mathrm{ml}$ (osmolaridad 285 
mOsm) lo cual cubre los requerimientos del lactante sin producirle una sobrecarga renal de solutos. En cambio en la leche de vaca el contenido es superior a $3.1 \mathrm{gr} / 100 \mathrm{ml}$ y su osmolaridad es de 350 mOsm, esto genera una sobrecarga renal de solutos, por lo que nunca se debe indicar leche de vaca durante el primer año de vida. La concentración de proteínas en la leche humana es menor en comparación con la de otros rumiantes, sin embargo es la cantidad necesaria para garantizar un crecimiento y desarrollo adecuado.

Otra diferencia entre la leche humana y la leche vacuna es la concentración de la lgA. Su concentración alcanza 100-140 mg/100ml en la leche materna y $3 \mathrm{mg} / 100 \mathrm{ml}$ en la leche de vaca fresca que al procesarla se inactiva. ${ }^{(4)}$

Los niños alimentados con fórmulas reciben un aporte proteico extra y por ende más energía en comparación con los alimentados al pecho exclusivo. Esto puede afectar de forma permanente su apetito, además de tener concentraciones más elevadas de insulina en sangre que estimula la acumulación de grasa y afecta el desarrollo temprano de los adipocitos.

La ingesta de proteínas tiene correlación más alta con el IMC que cualquier otro nutriente. Las cantidades altas de proteínas se metabolizan en el hígado provocando: Hígado graso; el cual es la manifestación hepática del síndrome metabólico y se asocia fuertemente a obesidad, DM tipo 2, HTA e hiperlipidemia y su prevalencia ha aumentado progresivamente a nivel mundial. ${ }^{(38-40)}$

El estudio ALSALMA, estudio realizado en España sobre la ingesta de nutrientes en menores de 3 años y publicado el 2015, muestra que el $95.9 \%$ de niños entre 7-36 meses de edad, presentan un exceso de proteínas en la ingesta diaria de nutrientes. ${ }^{(32)}$ La ingesta de proteínas superior al $20 \%$ del nivel basal puede perjudicar el balance hídrico, por tanto se deben evitar consumos proteicos elevados, sobre todo durante el primer año de vida. (32)
En el Childhood Obesity Research Demostration Project (CORD), estudio multicéntrico Europeo doble ciego y randomizado, se demuestra que los lactantes que reciben fórmulas de bajo contenido proteico, aunque dentro de los rangos recomendado por la ESPGHAN, presentan a los 6 años menos sobrepeso y obesidad que los niños lactados con fórmula de alto contenido proteico. ${ }^{(41-42)} \mathrm{La}$ lactancia materna previene la Obesidad, ya que cada mes de LM se asocia a una disminución del 4\% de riesgo. ${ }^{(33)}$ Un período de amamantamiento demasiado breve contribuye a incrementar el riesgo de obesidad futura. ${ }^{(35)}$

Otros factores de riesgo son los lactantes que están en el extremo superior en la distribución de peso o IMC o que crecen rápidamente durante los dos primeros años. La excesiva ganancia de peso durante los primeros 24 meses es el mejor predictor de sobrepeso en la edad escolar, y esto puede modificarse con una intervención temprana.

El sobrepeso y la obesidad no solo está determinada por los genes, sino que también la ingesta excesiva de proteínas en los primeros mil días de vida tienen mayor impacto en el futuro del niño.

\section{CONCLUSIÓN}

El reloj de los mil días no se puede reiniciar y debemos ser visionarios para mejorar la calidad de vida de los niños de manera oportuna. Es de vital importancia una correcta nutrición durante los primeros mil días para apoyar el crecimiento y desarrollo adecuado.

Con el fin de que los niños obtengan beneficios nutricionales e inmunológicos que necesitaran el resto de su vida, los pediatras tenemos una misión muy importante durante esta etapa crítica que es promover la lactancia materna exclusiva y adecuadas prácticas de alimentación, ya que los daños que se generen en este período tendrán consecuencias irreversibles. 


\section{BIBLIOGRAFÍA}

1. Pantoja M. Los primeros 1000 días de la vida. Rev Soc Bol Ped. 2015; 54 (2): 60 - 61.

2. Ruemmele FM. Early programming effects of nutrition-life-long Consequences? Ann Nutr Metab. 2011;58 (2):5-6

3. Hanson MA, Low FM, Gluckman PD. Epigenetic epidemiology: the rebirth of soth inheritance. Ann Nutri Metab. 2011; 58 (2): 8-15.

4. Raiten DJ, Raghavan R, Porter A, Obbagy JE, Spahn JM. Executive summary: evaluating the evidence base to support the inclusion of infants and children from birth to 24 mo of age in the Dietary Guidelines for Americans- "the B-24 Project". Am J Clin Nutr 2014; 99 (3):663S-91S.

5. Higuera J. Nutrición, crecimiento y desarrollo a partir del primer año de vida. México. 2011 p. 1-14.

6. Clayton H, Li R, Perrine CG, Scanlon KS. Prevalence and reasons for introducing infants early to solid foods: variations by milk feeding type. Pediatrics. 2013; 131 (4):1108-14.

7. Lopez MJ, Sánchez Jl, Sánchez MC, Domínguez M. Suplementos en embarazadas: controversias, evidencias y recomendaciones. Inf Ter Sist Nac Salud. 2010; 34(4):117-128.

8. Cattaneo A, Williams C, Pallas C, Hernandez M, Lasarte J, Landa L, et al. ESPGHAN's 2008 recommendation for early introduction of complementary foods: how good is the evidence? Maternal and Child Nutrition. 2011;7(4): 335-343.

9. Belderbos $M E$, Houben $M L$, van Bleek GM, Schuijff $L$, van Uden NO, Bloemen-Carlier EM, et al. Breastfeeding modulates neona- tal innate immune responses: a prospective birth cohort study. Pediatr Allergy and Immunol. 2012; 23(1): 65-74.

10. Mena P, Uauy R. Fats. En: Berthold Koletzko. Pediatric nutrition in practica. $2^{\mathrm{a}}$ ed. Switserland: Karger; 2015. p. 51-55.

11. Fewtrell M. Complementary Foods. En: Berthold Koletzko. Pediatric nutrition in practica. 2a ed. Switserland: Karger; 2015. p.109-112.

12. Carling S, Demment M, Kjolhede C, Olson C. Breastfeeding duration and weight gain trajectory in infancy. Pediatrics. 2015; 135 (1): 112-119.

13. EFSA Journal. Scientific Opinion on nutrient requirements and dietary intakes of infants and young children in the European Union. 2013; 11 (10):103.

14. American Academy of Pediatrics. Breastfeeding and the Use of Human Milk. Pediatrics. 2012;129 (3): 827-841.

15. ESPGHAN Committee on Nutrition, Agostoni C, Braegger C, Decsi T, Kolacek S, Koletzko B, Michaelsen KF, et al. Breast-feeding: A commentary by the ESPGHAN Committee on Nutrition. J Pediatr Gastroenterol Nutr. 2009; 49(1):112-25.

16. Dalmau J, Peña L, Moráis A, Martínez V, Varea $V$, Martínez MJ, et al. Análisis cuantitativo de la ingesta de nutrientes en niños menores de 3 años. An Pediatr (Barc). 2015; 8(4): 255-266.

17 Kleiman R. Breastfeeding. En: Pediatric nutrition handBook. 6a ed. Estados Unido: American Academy of Pediatria; 2009. P. 29-59.

18. Agostoni C, Braegger C, Decsi T, Kolacek S, 
Koletzko B, Michaelsen K, et al. Breast-feeding: a commentary by the ESPGHAN committee on nutrition. J Pediatr Gastroenterol Nutr. 2009; 49(1): 112-125.

19. Julia V, Macia L, Dombrowicz D. The impact of diet on asthma and allergic diseases. Nat Rev Inmunol. 2015; 15(5): 308-322.

20. Fleischer D, Spergel JM, Assa'ad AH, Pongracic JA. Primary prevention of allergic disease throughn nutritional interventions. J Allergy clin immunol pract. 2013; 1 (1): 29-36.

21. Rzehak P, Sausenthaler S, Koletzko S, Reinhardt D, von Berg A, Krämer $U$, et al. Long-term effects of hydrolyzed protein infant formulas on growth--extended follow-up to 10 y of age: results from the German Infant Nutritional Intervention (GINI) study. Am J ClinNutr. 2011; 94(6): 1803S-1807S.

22. Martorell R. Importancia de la nutrición durante los primeros mil dias de vida. El nidito. 2011;31.

23. Fernández $A$, Sosa $P$, Setton $D$, Desantadina V, Fabeiro M, Martínez MI, et al. Calcio y nutrición. Buenos Aires: Sociedad Argentina de Pediatría; 2011.

24. Grimshaw KE, Maskell J, Oliver EM, Morris RC, Fotte KD, Clare Mils E, et al. Diet and food allergy development during infancy: birth cohort study findings using prospective food diary data. J Alergy Clin Immunol. 2014; 133 (2): 511-19.

25. Hardwick J, Sidnell A. infant nutrition- diet between 6 and 24 months, implications for pediatrics growht overweight and obesity. Infant nutrition. 2014; 39(4): 354-363.

26. Sociedad Centroamericana de Gastroenterología Hepatología y nutrición Pediátrica. Primer Consenso centroamericano: alimenta- ción en el primer año de vida. Guatemala; Sociedad Centroamericana de Gastroenterología, Hepatología y Nutrición Pediátrica. 2015.

27. Boccolini CS, Carvalho ML, Oliveira MI, Pérez-Escamilla R. Breastfeeding during the first hour of life and Neonatol Mortality. Journal of Pediatric 2013; Vol 89 (2) 131-136.

28. Aecosan. Estrategia para la nutrición, actividad física y prevención de la obesidad. [Internet] Agencia española de consumo, seguridad alimentaria y nutrición. Alocala: Ministerio de Sanidad y Consumo. 2005. [Citado el 25 de diciembre 2016]. Disponible en: http://www.aecosan.msssi.gob.es/ AECOSAN/docs/documentos/nutricion/estrategianaos.pdf.

29. Ursell LK, Haiser HJ, Treuren W, Garg N, Reddivari L, Vanamala J, et al. The intestinal Metabolome- an Itersection Between Microbiota and Host. Gastroenterology. 2014; 146(6): 1470-1476.

30. Medicina Molecular de FIBAO http://medmol.es/glosario/109/. Fecha 10/11/2016. Término metaboloma.

31. Yajnik CS. Transmission of obesity-adiposity and related disorders from the mother to the baby. Ann Nutr Metab. 2014;64 (1):8-1.

32. Victora C. Los mil días de oportunidad para intervenciones nutricionales: de la concepción a los dos años de vida. Arch Argent Pediatr. 2012; 110(4):311-7.

33. Michaelsen KF. Breastfeeding. En: Berthold Koletzko. Pediatric nutrition in practica. $2^{a}$ ed. Switserland: Karger; 2015. p. 92-96.

34. Thorisdottir B, Gunnarsdottir I, Thorisdottir AV, Palsson GI, Halldorsson TI, Thorsdottir I. Nutrient intake in infancy and body mass index at six years in two population-based cohorts recruited before and after revision 
of infant dietary recommendations. Ann Nutr Metab 2013; 63 (1-2):145-151.

35. Van Goudoever JB. Protein. En: Berthold Koletzko. Pediatric nutrition in practice. $2 \mathrm{a}$ ed. Switserland: Karger; 2015. p. 41-45.

36. Hou Y, Yin Y, Wu G. Dietary essentiality of nutritionally non-essential amino acids for animals and humans. Expl Biol and Med (Maywood). 2015; 240 (8) 997-1007.

37. Zhiying Z, Adelman A, Rai D, Boettecher J, Lőnnerdal B. Amino acid profiles in term and preterm human milk through lactation: a systematic review. Nutrients. 2013; 5; 4800-4821.

38. Wagner P. Revisión crítica de los estudios de las alteraciones cognitivas y psicomotoras por deficiencia de hierro en la primera infancia ( 6 a 24 meses de edad). ANEMIA. 2010; 3 (3).

39. Miliku K, Voortman T, Bakker H, Hofman A,
Franco O, Jaddoe VW. Infant breastfeeding and kidney function in school-aged children. Am J Kidney Dis. 2015; 66 (3): 421-28.

40. Weber M, Grote V, Monasterolo R, Escribano J, Langhendries J, Dain E, et al. Lower protein content in infant formula reduces BMI and obesity risk at school age: follow-up of a randomized trial. Am J Clin Nutr 2014;99:1041-51.

41. Chalasani N, Younossi Z, Lavine J E. Diehl AM, Brunt E, Cusi K, et al. The diagnosis and management of non alcoholic fatty liver disease practice Guidelines by the american Association. For the study of liver disease. American college of gastroenterology association. Hepatology. 2012; 55 (6): 2005-2023.

42. Pearce J, Evans L. The types of food introduced during complementary feeding and isk of childhood obesity: a systematic review. Int J Obes 2013; 37(4):477-85. 